\title{
Post-activation depression of the lower extremities in stroke patients with spasticity and spastic equinovarus deformity
}

Depressão pós-ativação das extremidades inferiores de pacientes com acidente vascular cerebral que apresentam espasticidade e deformidade equinovarus por espasticidade

Yuanbin Yang, Juan Xiao, Weiqun Song

\begin{abstract}
This study aimed to investigate changes of post-activation depression in two groups of patients with or without spastic equinovarus deformity (SED). Paired and independent $t$-tests were used to compare post-activation depression within and between the groups, respectively. There was a significant positive correlation between diminished post-activation depression and spasticity severity. The soleus and tibialis anterior (TA) post-activation depression values were significantly decreased on the affected sides of patients with SED compared to those without. In patients without SED, the soleus post-activation depression was significantly decreased on the affected side; however, TA post-activation depression was higher on the affected side. Both the soleus and TA become active, but the onset time may be different. The imbalanced muscle tone between the soleus and TA in the early stage after stroke may be related to equinus deformity.
\end{abstract}

Keywords: stroke, spasticity, spastic equinovarus deformity, hemiplegia, rehabilitation.

\section{RESUMO}

O principal objetivo deste estudo é a investigação da depressão pós-ativação em pacientes com deformidade equinovarus espástica (DEE). Os pacientes foram divididos em dois grupos. Student-t testes pareados e independentes foram utilizados para comparar a depressão pósativação intra- e inter-grupos, respectivamente. Houve uma correlação positiva significativa entre a diminuição da depressão pós-ativação e a gravidade da espasticidade. A depressão pós-ativação dos músculos sóleo e tibial anterior (TA) estavam significativamente diminuídas no lado afetado dos pacientes com SEE em relação aos membros sem SEE. Em pacientes sem SEE, a depressão pós-ativação do músculo sóleo encontrava-se significativamente diminuída do lado afetado. No entanto, a depressão pós-ativação do músculo TA era maior no lado afetado que no lado não afetado. Tanto o sóleo quanto o TA serão ativados, mas o tempo para isso pode ser diferente. 0 desequilíbrio entre o tônus dos músculos sóleo e TA nos estágios iniciais pode estar relacionado à deformidade equina.

Palavras-chave: acidente vascular cerebral, espasticidade, deformidade equinovarus espástica, hemiplegia, reabilitação.

Spasticity is common in individuals with central nervous system (CNS) disease ${ }^{1}$. It causes pain and reduces voluntary movement, which can have a disabling effect on patients and negatively affect rehabilitation outcomes. Lance's widely used definition of spasticity states that spasticity is a motor disorder characterized by a velocity-dependent increase in tonic stretch reflexes (muscle tone) with exaggerated tendon jerks caused by stretch reflex hyperexcitability². A later 1994 definition described "a motor disorder characterized by a velocity-dependent increase in tonic stretch reflexes that results from abnormal intra-spinal processing of primary afferent input"3. A definition published in 2005 described spasticity as "disordered sensori-motor control, resulting from an upper motor neuron lesion, presenting as intermittent or sustained involuntary activation of muscles"4. There is general agreement that spasticity is caused by adaptations at the spinal cord level distal to the lesion.

Changes in spinal pathways may result in spasticity including altered muscle spindle sensitivity, presynaptic inhibition, recurrent (Renshaw) inhibition, Ib inhibition and facilitation, reciprocal Ia inhibition, group II facilitation, cutaneomuscular pathway changes, and post-activation depression ${ }^{5}$. The last item has been an invariant finding in spasticity ${ }^{1,6,7}$, and whether hemiplegic or spinal, this

Capital Medical University, Xuanwu Hospital, Department of Rehabilitation Medicine, Beijing, China.

Correspondence: Yuanbin Yang; Department of Rehabilitation Medicine, Xuanwu Hospital of Capital Medical University; 45 Changchun Street, Xicheng District, Beijing 100053, China; Email:yyb9471@aliyun.com

Conflict of interest: There is no conflict of interest to declare.

Received 28 November 2014; Received in final form 14 January 2015; Accepted 02 February 2015. 
abnormality correlates with the degree of spasticity ${ }^{7}$ and is not observed on the nonparetic side. Although it was reported that other pathways can be changed to different extents in patients with CNS lesions, contradictory results are published in the literature. However, most of these studies did not report a positive correlation between the degree of these abnormalities and spasticity severity. Therefore, it is presumed that post-activation depression may have some relationship with spasticity ${ }^{8}$.

If one H-reflex is induced in a resting state subject, then later stimulation will produce reflexes with lower amplitudes at intervals of up to $10 \mathrm{~s}$. Amplitude depression is termed post-activation depression or homosynaptic depres$\operatorname{sion}^{9,10,11,12}$. The degree of depression depends on the interstimulus time: the shorter the time, the more obvious the depression ${ }^{13}$. H-reflex depression is striking at short breaks (1-2 s between two successive stimulations). In contrast, the depression is not obvious when the stimulation intervals are $8 \mathrm{~s}$ or longer 7 . Decreased synaptic neurotransmitter release may be responsible for the depression, which is most obvious in resting individuals and is weak or absent when the tested muscle is voluntarily activated ${ }^{8,10}$.

To date, most reports have only measured flexor carpi radialis (FCR) and soleus post-activation depression. To our knowledge, there is no report on post-activation depression of the tibialis anterior (TA). The TA may also become spastic in post-stroke hemiplegia patients, which is one of the reasons for spastic equinovarus deformity (SED). Therefore, the first aim of this study was to investigate soleus and TA post-activation depression changes in patients with SED. Our second aim was to demonstrate that TA post-activation depression impairment can also reflect spasticity severity. We also confirmed the previously reported finding that reduced soleus post-activation depression is related to spasticity.

\section{METHOD}

\section{Patients}

This study was carried out in the Department of Rehabilitation, Xuanwu Hospital of Capital Medical University. All patients had suffered a first stroke. Cerebral lesions were visualized on brain computed tomography (CT) or magnetic resonance imaging (MRI). All the patients and their guardians provided written informed consent for the experimental procedure, and the hospital ethics committee approved this study.

To investigate the relationship between post-activation depression and spasticity, we assessed 33 stroke patients (6 females and 27 males) aged 25-65 (48.94 \pm 9.87 years). The time since the stroke ranged from 11 to 190 days $(85.97 \pm 67.45)$. Abnormal muscle tone was assessed with the composite spasticity index (CSI). The maximum possible CSI score are $16^{14}$. The assessment was performed by a professional physiotherapist who was blinded to the post-activation depression findings.

To investigate changes in both TA and soleus post-activation depression in patients with or without SED following stroke, the subjects were divided into two groups: I, hemiplegia patients with SED after stroke $(\mathrm{n}=15)$ and II, hemiplegia patients without SED after stroke $(\mathrm{n}=18)$. There was no significant difference between the two groups with regard to age, sex, paretic side, or diagnosis.

\section{$\mathrm{H}$-reflex test}

The subjects were instructed to lie in a comfortable supine position. The soleus and TA H-reflexes were induced and recorded using a VikingQuest device (Nicolet Biomedical, Madison, WI, USA). We used self-adhesive Ag-AgCl electrodes ( $1.0 \mathrm{~cm}$ diameter) to record surface electromyography signals. The recording electrodes were fixed to the corresponding skin over the muscle bellies, and the reference electrode was secured to the skin over the muscle tendon. The ground electrode was secured between the recording and reference electrodes.

The tibial nerve and common fibular nerve were stimulated by a surface bipolar electrode (active cathode in the proximal part, anode in the distal part) using 1-s percutaneous electrical pulses. The stimulation intensity started at $0 \mathrm{~mA}$ and increased in 2-mA steps at a frequency of $0.2 \mathrm{~Hz}$ until the H-reflex disappeared. The magnitude of the response was measured as the peak-to-peak amplitude of the reflex. Figure 1 shows the wiring diagram to measure soleus and TA H-reflex pathways.

\section{Post-activation depression of the H-reflex}

To determine post-activation depression, the stimulation intensity was set to the level that elicited H-reflex amplitudes at the size of Hmax/2. M-waves were present in all subjects at this intensity. Sixteen consecutive H-reflexes were acquired at 0.1 and $1 \mathrm{~Hz}$, and again at $0.1 \mathrm{~Hz}$. The stability of M-wave size was thoroughly monitored in each session. The second train of $0.1 \mathrm{~Hz}$ was administered to confirm that the H-reflex recovered to its original size after the $0.1-\mathrm{Hz}$ stimulation had ended and to guarantee that activation remained unchanged throughout the sessions. The amount of post-activation depression was computed in each patient by normalizing the mean size of 1-Hz-induced H-reflex to the mean size of the $0.1-\mathrm{Hz}$ condition after elimination of the first wave $\mathrm{e}^{15}$. This is called the $1 / 10$ s ratio, and a greater value indicates less postactivation depression. Special attention was paid to ensure that the tested muscle was at complete rest because post-activation depression is reduced when the muscle is voluntarily contracted ${ }^{7}$. Post-activation depression was determined bilaterally. Figures 2 and 3 show the changes of soleus and TA H-reflex amplitudes with different electrical stimulus rates in hemiplegia patients with lower-extremity spasticity. 
A

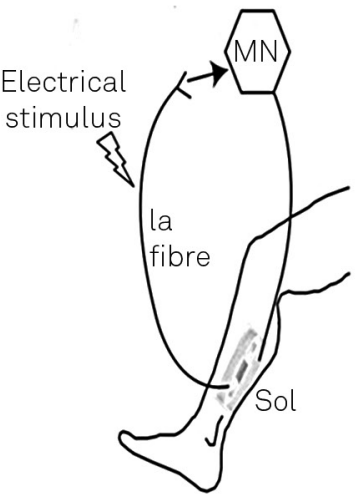

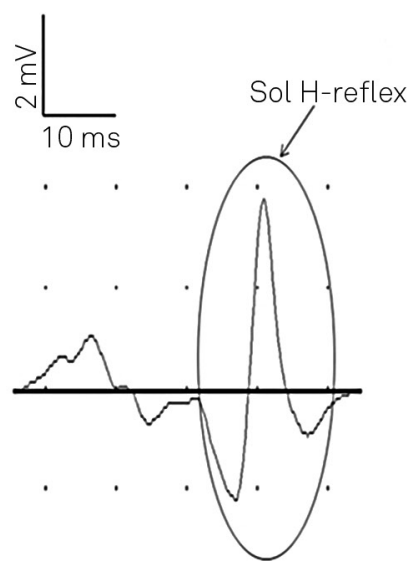
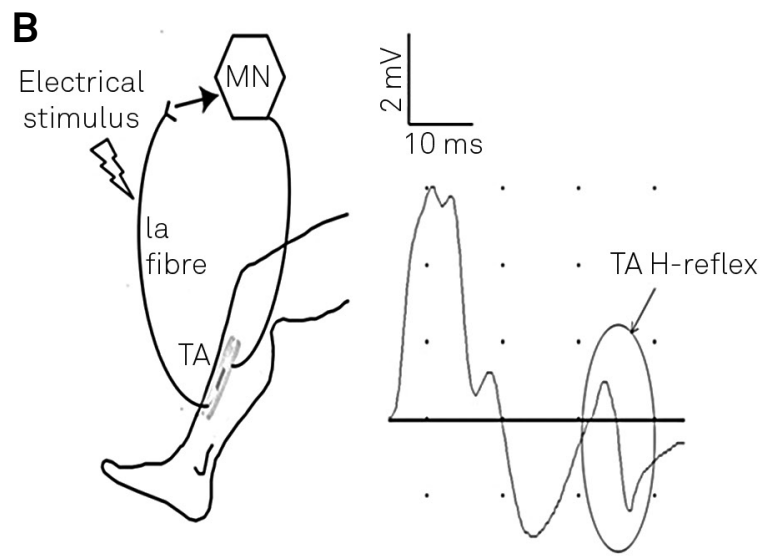

Figure 1. Wiring diagram of pathways of soleus (A) and TA (B) H-reflexes. MN: motoneuron. Sol: soleus.

\section{Statistical analysis}

All analyses were performed with SPSS (version 13; SPSS Inc., Chicago, IL, USA). Kolmogorov-Smirnov and equality of variances tests were used to check normality for data in each group. Paired $t$-tests were applied to compare soleus post-activation depression between the unaffected and affected sides (patients with SED and patients without SED, respectively). Comparisons of the TA post-activation depression between the unaffected and affected sides also used paired $t$-tests (patients with and without SED, respectively). Independent $t$-tests were performed to compare soleus post-activation depression between patients with and without SED (affected and unaffected sides, respectively). Comparisons of the TA post-activation depression between patients with SED and patients without SED were made using paired $t$-tests (affected and unaffected sides, respectively). Spearman's correlation coefficient tests were used to explore the relationship between spasticity severity and the decrease in post-activation depression. For all tests, $\mathrm{p}<0.05$ was considered statistically significant.

\section{RESULTS}

Spearman's coefficients were used to investigate the relationship between post-activation depression (1/10s ratio) and spasticity severity (CSI) (Figure 4). Both the reduced post-activation depression (implied by an increase of the $1 / 10$ s ratio) of soleus $(\mathrm{r}=0.676, \mathrm{p}<0.001)$ and TA $(\mathrm{r}=0.743$, $\mathrm{p}<0.001$ ) were significantly positively correlated with CSI. In other words, the larger the decrease in post-activation depression, the greater the degree of spasticity.

The $1 / 10$ s ratios of the soleus and TA were assessed in stroke patients and were significantly increased on the affected side of patients with SED compared with the affected side in patients without SED (soleus, $p=0.001$; TA, $p<0.001$ ). In patients with SED, the $1 / 10$ s ratios of both the soleus and
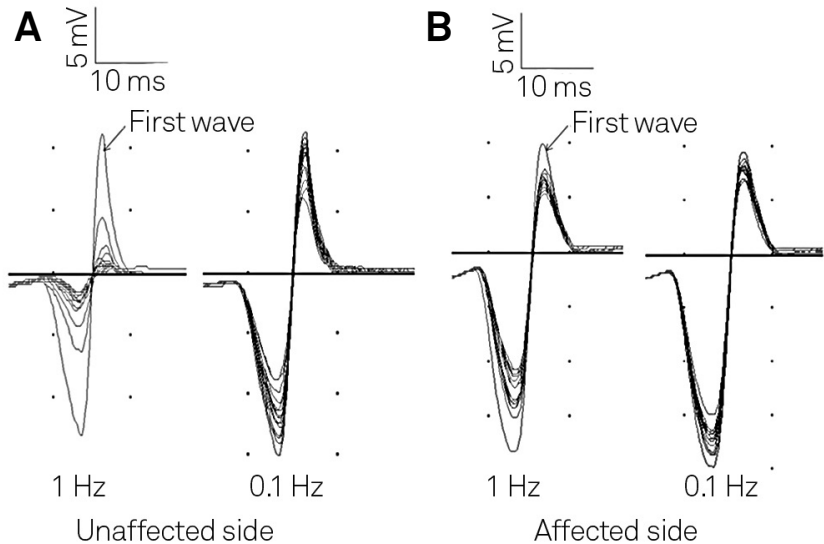

Affected side

Figure 2. The changes of soleus $\mathrm{H}$-reflex amplitude with different electrical stimulus rate in a hemiplegia patient with lower extremity spasticity. We can see that when high-frequency $(1-\mathrm{Hz})$ electrical stimulus was applied, the second and later $\mathrm{H}$-reflex amplitude decreased significantly compared to the first $\mathrm{H}$-reflex on the unaffected side. However, on the affected side, the second and later $\mathrm{H}$-reflex amplitude also decreased, but to a much lesser extent compared to the unaffected side, and the post-activation depression of the affected side is impaired. When low-frequency $(0.1-\mathrm{Hz})$ electrical stimulus was applied, the $\mathrm{H}$-reflex amplitude of both the unaffected side and the affected side did not decrease significantly.

TA were significantly increased on the affected side compared to the unaffected side (soleus, $\mathrm{p}<0.001$; TA, $\mathrm{p}<0.001$ ). In patients without SED, the $1 / 10$ s ratio of the soleus was significantly increased on the affected side compared to the unaffected side $(p=0.001)$. However, the $1 / 10$ s ratio of the TA was lower on the affected side compared to the unaffected side $(\mathrm{p}<0.001)$.

We also compared the time since stroke between the two groups using an independent $t$-test. In patients with and without SED, the mean times were 123.73 and 25.87 days, respectively. The time difference between the two groups was significant $(\mathrm{p}<0.001)$. 


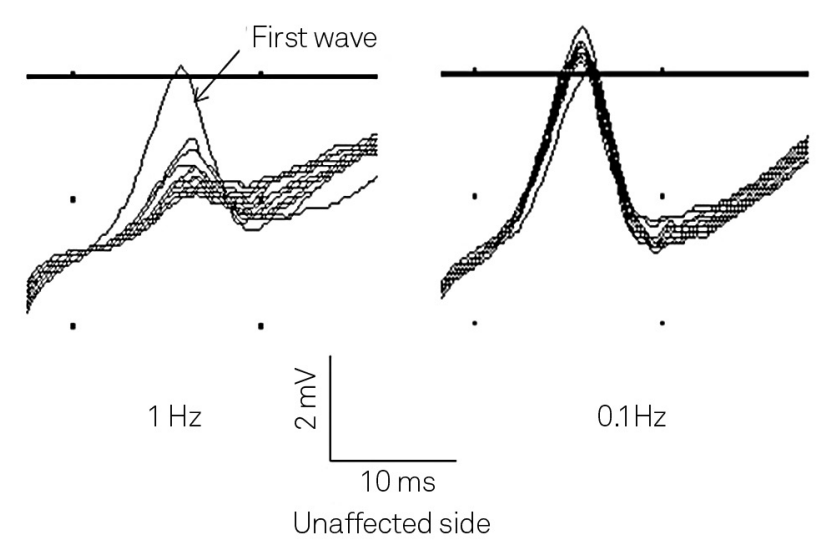

Figure 3. The changes of TA H-reflex amplitude with different electrical stimulus rate on the unaffected side of a hemiplegia patient. We can see that when high-frequency $(1-\mathrm{Hz})$ electrical stimulus was applied, the second and later $\mathrm{H}$-reflex amplitude decreased significantly compared to the first $\mathrm{H}$-reflex. When low-frequency $(0.1-\mathrm{Hz})$ electrical stimulus was applied, the $\mathrm{H}$-reflex amplitude did not decrease significantly.

\section{DISCUSSION}

There were five major findings of this study. (i) The most interesting finding is that in patients without SED, soleus postactivation depression decreased on the affected side compared to the unaffected side; conversely, TA post-activation depression was higher on the affected side compared to the unaffected side. (ii) Post-activation depression was decreased on the affected side compared to the unaffected in patients with SED, and post-activation depression (both soleus and TA) was decreased in patients with SED compared to patients without SED on the affected side. (iii) Most patients with SED were in the subacute or chronic stage, while patients without SED were in the early stage or had mild hemiplegia. (iv) Significant positive correlations were found between both diminished soleus/TA post-activation depression and spasticity severity.

Previous studies have revealed a significant positive correlation between reduced post-activation depression and spasticity severity ${ }^{6,7}$. Our results provide additional evidence for this relationship. A longitudinal observation of one patient with spinal cord injury (SCI) showed that the decrease of post-activation depression developed with the transition from flaccid to spastic paralysis ${ }^{16}$. After CNS lesions, post-activation depression gradually lessens as patients transition from the acute to chronic state, which mimics the evolution of spasticity ${ }^{17,18}$. Although there is no definitive proof, previous studies and our findings indicate that reduced post-activation depression is one of the mechanisms underlying spasticity. Most reports only measured FCR and soleus post-activation depression; we have not seen any reports studying TA post-activation depression. The TA may also become spastic in post-stroke hemiplegia patients. We

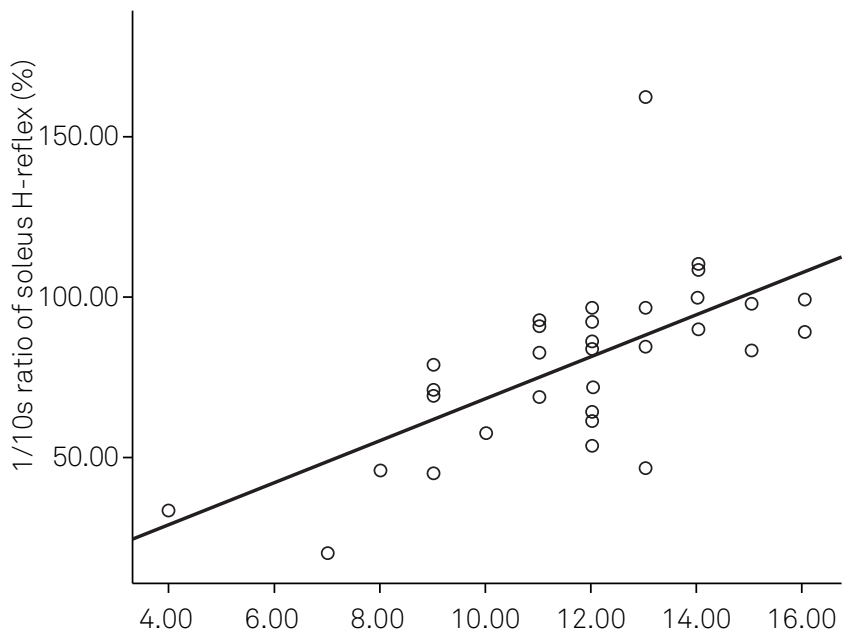

CSI

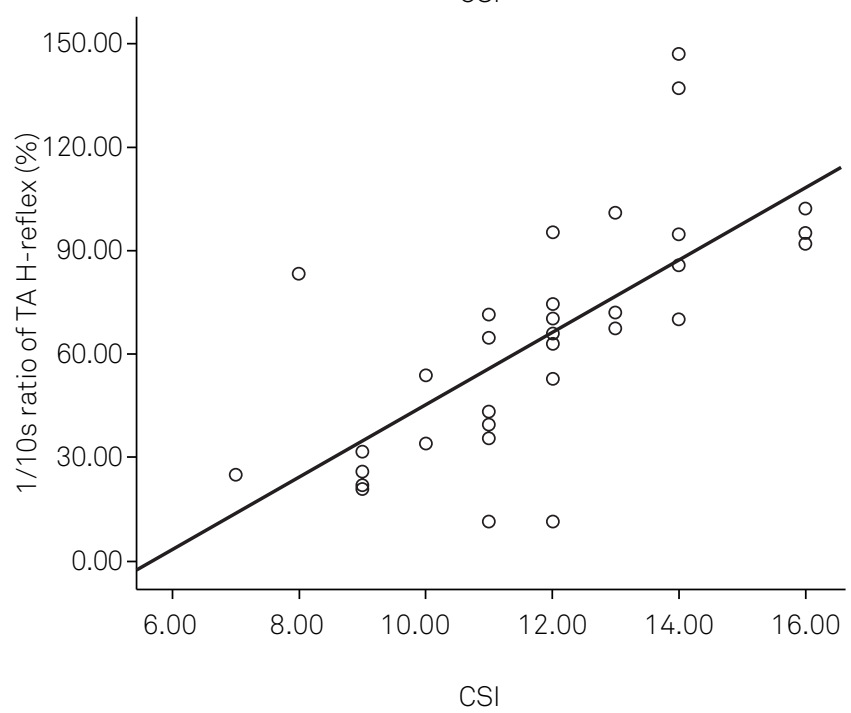

CSI: composite spasticity index; TA: tibialis anterior.

Figure 4. Correlation between the post-activation depression size and CSI. The amount of post-activation depression was indicated by the $1 / 10$ s ratios. The greater the $1 / 10$ s ratio, the smaller the post-activation depression. Left: soleus, data from 33 participants. Right: TA, data from 33 patients. Each small circle represents one patient. The lines in the charts are the regression lines. The correlation coefficient of the Spearman rank tests was 0.676 and 0.743 , respectively (significant at the 0.001 level).

found that TA post-activation depression also correlated with spasticity severity as assessed by CSI.

SED is a common pattern of neurological impairment that limits patients' ability to walk. This deformity is reported in $18 \%$ of stroke patients ${ }^{19}$. SED includes equinus, varus, and claw toe deformities. Equinus deformity is caused by imbalanced muscle tone of the plantar flexor (higher) and dorsal flexor (lower), while varus deformity is associated with imbalanced muscle tone of the inversion (higher) and evertor muscles (lower). After cerebral lesioning, the prolonged increased muscle tone of the hemiplegic extremity would cause triceps shortening and tendon and soft tissue contracture, which are related to SED. 
The inversion muscles of the foot include the TA and tibialis posterior, while the main evertor muscle is the peroneal muscle. The dorsal flexion muscles include the TA, extensor hallucis longus, and extensor digitorum longus. The plantar flexors comprise the peroneal muscle, triceps, flexor digitorum longus, tibialis posterior, and flexor hallucis longus. The TA is the main dorsal flexion and inversion muscle, while the soleus is one of the most important plantar flexion muscles. The volumes of the two muscles are large and their locations are superficial, making them easy to assess. Therefore, this study only measured the two muscles.

Based on our studies and clinical experience, SED is more likely to appear in subacute and chronic stage patients, while most patients without SED have had a recent stroke. Several studies have found that post-activation depression impairments do not appear immediately after the lesion but a few weeks later, indicating that the reduction of post-activation depression occurs gradually over time ${ }^{7}$. The decrease of post-activation depression observed in spastic patients and the temporal changes in the depression in the months after SCI mimic spasticity progress ${ }^{20}$. Spasticity, SED, and impaired post-activation depression appear gradually rather than immediately after CNS lesion. These changes take time to develop and thus may be due to lesion-induced changes in supraspinal controls and plastic changes in the spinal cord that are secondary to the loss of the supraspinal drive disrupted by the CNS lesion ${ }^{7}$. Impaired post-activation depression may be one of the important plastic changes at the spinal cord level. Based on the above arguments, it is likely that SED is related to muscle spasticity resulting from spinal cord plasticity (such as post-activation depression changes), and this change in plasticity requires a certain amount of time after CNS damage.

Interestingly, in patients without SED, soleus post-activation depression significantly diminished on the affected side compared to the unaffected side. Conversely, TA post-activation depression was higher on the affected side. It may be that soleus muscle tone increases first but cannot be detected by clinical scales. At the same time, the TA is still in the flaccid paralysis stage, which is reflected by the high level of post-activation depression. However, muscle tone increases with time. The earlier increase in soleus muscle tone may be due to the appearance of a more primitive pattern of locomotor synergy that allows simultaneous contractions of the hip, knee, and ankle extensors. Therefore, in spastic hemiplegia patients, both the agonist and antagonist (when plantar flexion occurs, the soleus and TA, respectively) will become active to some extent. However, the onset time may be different. The imbalance of muscle tone between the soleus and TA in the early stage may be related to equinus deformity.

Unfortunately, we did not examine the post-activation depression of the peroneal muscle for technical reasons. When this inversion occurs, the TA is the agonist and the peroneal muscle is the antagonist. Although the post-activation depression of the peroneal muscle was not tested, we deduced that the impaired post-activation depression of peroneal muscle may also occur later than for the TA, which is related to the varus deformity, just as impaired post-activation depression of TA occurs later than that of the soleus. Future studies are needed to confirm our hypothesis.

In conclusion, decreased post-activation depression may be an electrophysiological expression of spasticity. In spastic hemiplegia patients, both the soleus and TA will become active to some extent during plantar flexion, but the onset times may be different. The imbalance of muscle tone between the agonist and antagonist in early stages may result in a specific deformity. Post-activation depression may be a potential objective index for measuring spasticity. It may also be used to assess the effectiveness of rehabilitation therapy. Early measurement may help physicians to predict and prevent spasticity and avoid joint deformity.

\section{References}

1. Grey MJ, Klinge K, Crone C, Lorentzen J, Biering-Sørensen F, Ravnborg M et al. Post-activation depression of soleus stretch reflexes in healthy and spastic humans. Exp Brain Res. 2008;185(2):189-97. http://dx.doi.org/10.1007/s00221-007-1142-6

2. Lance JW. Disordered muscle tone and movement. Clin Exp Neurol. 1981;18:27-35.

3. Young RR. Spasticity: a review. Neurology. 1994;44(11 Suppl 9):S12-20.

4. Pandyan AD, Gregoric M, Barnes MP, Wood D, Van Wijck F, Burridge $J$ et al. Spasticity: clinical perceptions, neurological realities and meaningful measurement. Disabil Rehabil. 2005;27(1-2):2-6. http://dx.doi.org/10.1080/09638280400014576

5. Burke D, Wissel J, Donnan GA. Pathophysiology of spasticity in stroke. Neurology. 2013;80(2 Suppl 2):S20-6. http://dx.doi.org/10.1212/WNL.0b013e31827624a7

6. Achache V, Roche N, Lamy JC, Boakye M, Lackmy A, Gastal A et al. Transmission within several spinal pathways in adults with cerebral palsy. Brain. 2010;133(5):1470-83. http://dx.doi.org/10.1093/brain/awq053
7. Lamy JC, Wargon I, Mazevet D, Ghanim Z, Pradat-Diehl P, Katz R. Impaired efficacy of spinal presynaptic mechanisms in spastic stroke patients. Brain. 2009;132(3):734-48. http://dx.doi.org/10.1093/brain/awn310

8. Phadke CP, Flynn SM, Thompson FJ, Behrman AL, Trimble $\mathrm{MH}$, Kukulka CG. Comparison of single bout effects of bicycle training versus locomotor training on paired reflex depression of the soleus $\mathrm{H}$-reflex after motor incomplete spinal cord injury. Arch Phys Med Rehabil. 2009;90(7):1218-28. http://dx.doi.org/10.1016/j.apmr.2009.01.022

9. Trompetto C, Marinelli L, Mori L, Canneva S, Colombano F, Traverso $E$ et al. The effect of age on post-activation depression of the upper limb H-reflex. Eur J Appl Physiol. 2014;114(2):359-64. http://dx.doi.org/10.1007/s00421-013-2778-5

10. Stein RB, Estabrooks KL, McGie S, Roth MJ, Jones KE. Quantifying the effects of voluntary contraction and inter-stimulus interval on the human soleus H-reflex. Exp Brain Res. 2007;182(3):309-19. http://dx.doi.org/10.1007/s00221-007-0989-x 
11. Tseng SC, Shields RK. Limb compressive load does not inhibit post activation depression of soleus $\mathrm{H}$-reflex in indiviudals with chronic spinal cord injury. Clin Neurophysiol. 2013;124(5):982-90. http://dx.doi.org/10.1016/j.clinph.2012.10.020

12. Johnson ST, Kipp K, Norcross MF, Hoffman MA. Spinal and supraspinal motor control predictors of rate of torque development. Scand J Med Sci Sports. 2014. http://dx.doi.org/10.1111/sms.12283

13. Nielsen J, Petersen N, Ballegaard M, Biering-Sørensen F, Kiehn O. $\mathrm{H}$-reflexes are less depressed following muscle stretch in spastic spinal cord injured patients than in healthy subjects. Exp Brain Res. 1993;97(1):173-6. http://dx.doi.org/10.1007/BF00228827

14. Bi S, Wan CX. Comparison of the reaction time of wrist flexion and extension between patients with stroke and age-matched healthy subjects and correlation with clinical measures. Chin Med J (Engl). 2013;126(13):2485-8.

15. Winkler T, Hering P, Straube A. Spinal DC stimulation in humans modulates post-activation depression of the $\mathrm{H}$-reflex depending on current polarity. Clin Neurophysiol. 2010;121(6):957-61. http://dx.doi.org/10.1016/j.clinph.2010.01.014
16. Hiersemenzel LP, Curt A, Dietz V. From spinal shock to spasticity: neuronal adaptations to a spinal cord injury. Neurology. 2000;54(8):1574-82. http://dx.doi.org/10.1212/WNL.54.8.1574

17. Shields RK. Muscular, skeletal, and neural adaptations following spinal cord injury. J Orthop Sports Phys Ther. 2002;32(2):65-74. http://dx.doi.org/10.2519/jospt.2002.32.2.65

18. Schindler-Ivens S, Shields RK. Low frequency depression of H-reflexes in humans with acute and chronic spinal-cord injury. Exp Brain Res. 2000;133(2):233-41. http://dx.doi.org/10.1007/s002210000377

19. Bollens B, Gustin T, Stoquart G, Detrembleur C, Lejeune $\mathrm{T}$, Deltombe T: A randomized controlled trial of selective neurotomy versus botulinum toxin for spastic equinovarus foot after stroke. Neurorehabil Neural Repair. 2013;27(8):695-703. http://dx.doi.org/10.1177/1545968313491002

20. Aymard C, Katz R, Lafitte C, Lo E, Pénicaud A, Pradat-Diehl P et al. Presynaptic inhibition and homosynaptic depression: a comparison between lower and upper limbs in normal human subjects and patients with hemiplegia. Brain. 2000;123(8):1688-702. http://dx.doi.org/10.1093/brain/123.8.1688 